\title{
Evaluation of Shear and Tensile Bridging Characteristics of PVA Fibers Based on Bridging Law
}

\author{
Yuriko Ozu ${ }^{1}$, Hiroshi Yamada ${ }^{2}$, Akira Yasojima ${ }^{3}$, Toshiyuki Kanakubo ${ }^{4}$ \\ ${ }^{1}$ Department of Engineering Mechanics and Energy, University of Tsukuba, 1-1-1, \\ Tennohdai, Tsukuba, 305-8573, Japan; PH +81(29)853-5462; FAX +81(29)853-5207; \\ email: s1620871@u.tsukuba.ac.jp \\ ${ }^{2}$ Konoike Construction Co. Ltd., 3-6-1 Kitakyuhojimachi, Chuo-ku, Osaka, 541- \\ 0057, Japan \\ ${ }^{3}$ Department of Engineering Mechanics and Energy, University of Tsukuba, 1-1-1, \\ Tennohdai, Tsukuba, 305-8573, Japan; PH +81(29)853-5257; FAX +81(29)853-5207; \\ email: yasojima@kz.tsukuba.ac.jp \\ ${ }^{4}$ Department of Engineering Mechanics and Energy, University of Tsukuba, 1-1-1, \\ Tennohdai, Tsukuba, 305-8573, Japan; PH +81(29)853-5045; FAX +81(29)853-5207; \\ email:kanakubo@kz.tsukuba.ac.jp
}

\begin{abstract}
Strain-Hardening Cementitious Composites (SHCC), in which short fibers are mixed in mortar, show improved tensile performance and ductility of the cementitious material because fibers bridging the crack transfer tensile forces after first cracking. It is considered that the stress field at the shear crack surface in the structural element under the shear force is a biaxial stress field in which tensile and shear stresses exist concurrently. In fiber-reinforced cementitious composites, both tensile and shear stresses are transmitted via fibers that bridge shear cracks. It is necessary that the effect of fibers bridging a shear crack under tensile and shear stresses is investigated. In this study, uniaxial tension tests were carried out for specimens which have a square cross-section and an inclined notch. The biaxial stress field can be expressed by the inclined crack surface produced by the tensile loading. From the test results, it was confirmed that the tensile stress decreased with increasing notch angle in the tension tests. A calculation method for the bridging law with an inclined crack was introduced and the calculation results were compared with the test results. Though the maximum tensile stress in the tests was smaller than that in the calculation results, the curves after the maximum stress show good agreements with the calculations. The maximum stress reached in the tests tends to decrease with increasing crack angle (notch angle) as in the calculation results.
\end{abstract}

Keywords: Bridging law, Crack angle, Biaxial stress, Tension test, Notched specimen

\section{INTRODUCTION}

Strain-Hardening Cementitious Composites (SHCC) shows improved strength and ductility of members because of the effect of bridging after first cracking. It is imperative to research the structural performance of SHCC for promotion of 
utilization. In the previous study (Yamada, et al. 2016), the loading test of precast beam-column joints using fiber-reinforced cementitious composites (FRCC) with PVA fiber in panel zone was conducted to evaluate the shear performance of joint panel. The maximum load of the specimen in which the volume fraction of PVA fiber was $2.0 \%$ became dramatically larger than that of the specimen without fiber. Moreover, it was confirmed that the damage of the panel zone decreased due to the bridging effect of PVA fibers because the cracks dispersed and the increment of the crack width was inhibited as compared with the non-fiber specimen. However, the stress transferring mechanism of fibers in shear crack surface is not clarified. In this previous study, it was assumed that the stress field at the shear crack surface in panel zone is the biaxial stress field in which tensile and shear stresses exist concurrently. Principal crack opening (displacement toward a principal stress), crack width (displacement toward the perpendicular direction to a shear crack), and crack sliding (displacement toward a shear crack) were obtained from the experiment results as shown in Figure 1. The crack width and the crack sliding increased with the progress of the deformation. In usual RC members, it is considered that shear stress in crack surface is transferred owing to the bearing action of coarse aggregate and Dowel action by reinforcement. In case of FRCC, however, shear stress is transferred owing to the tensile forces of fibers bridging a crack. Therefore, it is essential to clarify the relationship between stress in the perpendicular direction to a shear crack and crack width, and the relationship between stress along a shear crack and crack sliding, to evaluate the bridging performance of fibers on shear crack surface.

On the other hands, tensile performance of FRCC is characterized by tensile stress crack width relationship called bridging law (Kanda and Li 1999, Yan, et al. 2008, Kanakubo, et al. 2016). Bridging law is calculated by the summation of the pullout behavior of each single fiber in crack surface based on pullout tests of single fiber. The bridging law is good agreement with the tension test result.

In this study, the bridging law considering the behavior of fibers in shear crack surface is calculated, and uniaxial tension tests are conducted for specimens which have a square cross-section and an inclined notch to simulate the biaxial stress field (Figure 2). As shown in Figure 2, the specimen in the biaxial stress field (left side figure) is turned (central figure), and then, it is assumed that biaxial stress field can be expressed by the tension test of the inclined notch specimen (right side figure). The evaluation based on the bridging law is verified to compare the test results with the calculation results of the bridging law. In this study, PVA fiber with diameter of 0.10 $\mathrm{mm}$ is applied. Though PVA fiber with finer diameter than $0.10 \mathrm{~mm}$ is generally used for SHCC, the bridging law cannot be directly obtained due to multiple cracking.
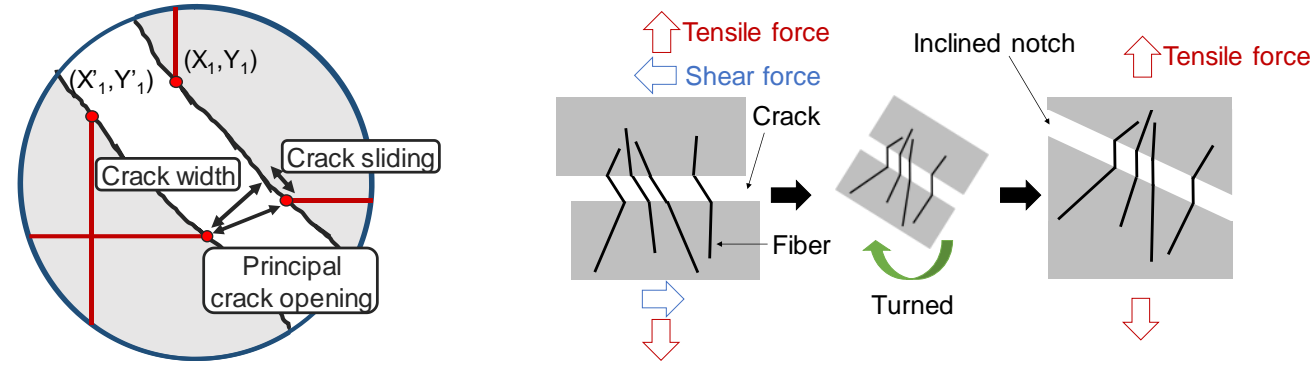

Figure 1. Evaluation of crack width. Figure 2. Simulation of biaxial stress field. 


\section{BRIDGING LAW CALCULATION WITH CRACK ANGLE}

Bridging law when crack angle equals 0 deg. The definition of crack angle is shown in Figure 3. The crack angle is equal to $0^{\circ}$ when the crack surface is perpendicular to the axial direction of specimens. In the previous study (Kanakubo, et al. 2016), tensile behavior of FRCC is accurately evaluated by calculating bridging law at the crack surface in a tension test, i.e., in the case of crack angle $0^{\circ}$.

Bridging law is based on the model of the pullout property (the relationship between pullout load and pullout displacement) of single fiber obtained by pullout tests. The model applied in this study is shown in Figure 4 and the input values to the parameter of the model is shown in Table 1. The definitions of the symbols in Figure 4 are shown in Table1. Snubbing coefficient in Table 1 expresses the value of increment of pullout load when fiber has orientation angle with normal direction of crack surface. Fiber strength reduction factor in Table 1 expresses the value of fiber strength degradation due to damage of fibers by orientation angle. The pullout property of single fiber based on pullout tests is applied to each single fiber at crack surface.

At the same time, it is well known that fiber orientation is strongly affected by flow of matrix, specimen size and so on. In order to assign the effect of orientation angle to each single fiber in crack surface, the fiber orientation distribution is given by a probability density function (PDF) as shown in Figure 5 (Kanakubo, et al. 2016). The difference of fiber orientation is quantitatively expressed by the value of orientation intensity $k$ in the PDF. When the fibers tend to orient to the axial direction, the value of $k$ becomes larger than 1, and when they orient to the perpendicular direction to the axial direction, the value of $k$ becomes smaller than 1 . The random orientation is given as the value of $k=1$.

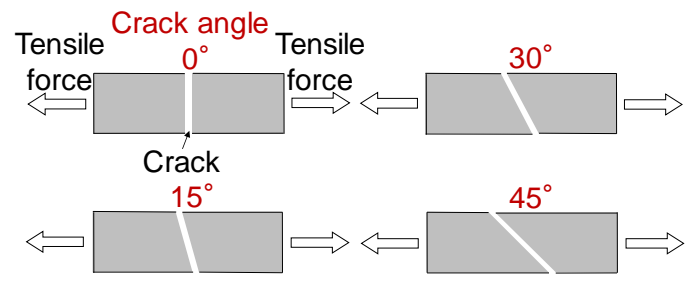

Figure 3. Crack angle

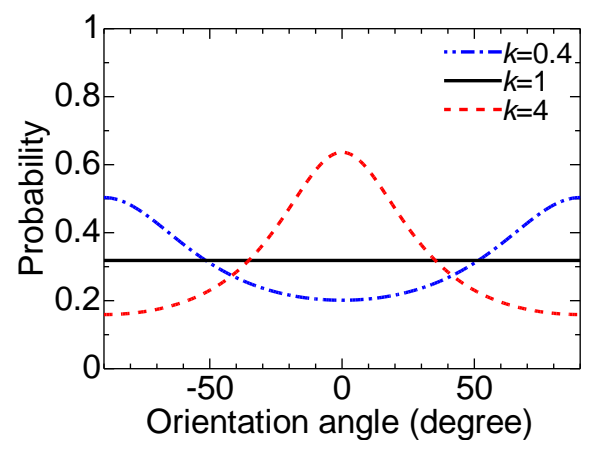

Figure 5. Elliptic distribution

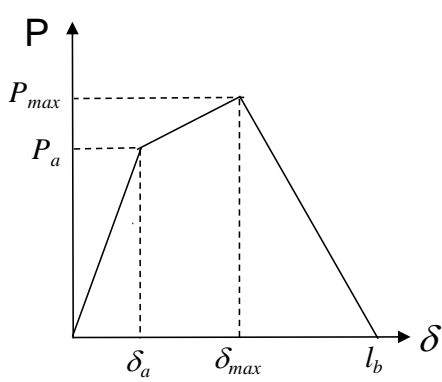

Figure 4. Pullout model of single fiber
Table 1. Input values for pullout model.

\begin{tabular}{c|c}
\hline Item & Value \\
\hline First peak load, $P_{a}(\mathrm{~N})$ & 1.5 \\
Crack width at $P_{a}, \delta_{a}(\mathrm{~mm})$ & 0.2 \\
Maximum load, $P_{\max }(\mathrm{N})$ & 3.0 \\
Crack width at $P_{\max }, \delta_{\max }(\mathrm{mm})$ & 0.45 \\
Fiber strength, $\sigma_{f u},(\mathrm{MPa})$ & 774 \\
Snubbing coefficient, $f$ & 0.5 \\
Fiber strength reduction factor, $f$ & 0.3 \\
Fiber length, $l_{f}(\mathrm{~mm})$ & 12 \\
\hline
\end{tabular}


Bridging law when crack angle inclines. Figure 6 illustrates the concept of bridging law calculation when the fibers has inclined crack angle. The left side figure in Figure 6 shows each orientation angle of three fibers $\left(\theta_{1}, 0^{\circ}, \theta_{2}\right.$ from right to left) when only tensile force is applied to a specimen in the case of crack angle $0^{\circ}$. Central figure in Figure 6 shows a case when tensile force and shear force concurrently act on these three fibers. If the angle to vertical direction of the fiber of orientation angle $0^{\circ}$ is $\theta_{i n i}$, each orientation angle of three fibers increase by $\theta_{i n i}$. Therefore, the bridging law when a specimen has the inclined crack can be calculated by increasing orientation angle by $\theta_{\text {ini }}$ (right side figure in Figure 6).

The calculated bridging law considering crack angle is shown in Figure 7. Orientation intensity $k$ is set to 1 . All curves in Figure 7 show the tendency which tensile stress increases to maximum stress from initial gradient, after that, tensile stress gradually decreases. The maximum tensile stress decreases with increasing crack angle. It is considered that the effect of fiber strength degradation due to orientation angle is higher than the effect of the strength increment due to snubbing effect.

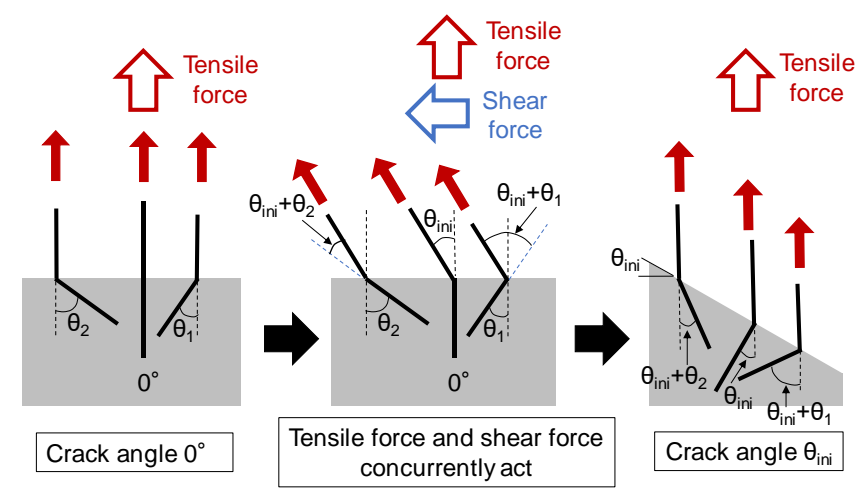

Figure 6. Fibers with inclined crack angle.

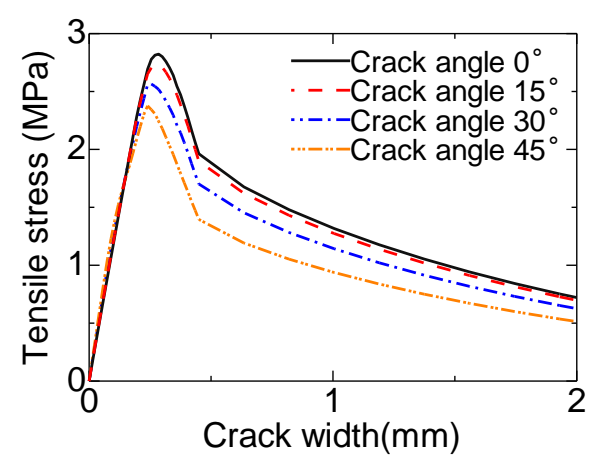

Figure 7. Bridging law

\section{UNIAXIAL TENSION TEST}

Materials and specimens. The mechanical properties of PVA fiber applied in this study are shown in Table 2 and the mix proportion is shown in Table 3 . The volume fraction of PVA fiber is $2.0 \%$. FRCC is continuously poured from the edge of the mold. The compression test results and the fresh properties are shown in Table 4.

The dimension of specimens is shown in Figure 8. The cross-section of the specimens is $100 \times 100 \mathrm{~mm}$ and the length of the specimen is comparatively long $600 \mathrm{~mm}$ to prevent the pouring effect to fiber orientation at central position. The tensile load is transferred through screw rods whose edge is obliquely manufactured to avoid sharp change of the stiffness in a specimen. The experimental parameter is notch angle (crack angle), $0^{\circ}, 15^{\circ}, 30^{\circ}$, and $45^{\circ}$. The number of specimens of each parameter is three. The detail of notch is shown in Figure 9. Notch is set along the four sides on the periphery to cause inclined crack exactly. The area of the ligament is constant (70 $\mathrm{mm} \times 70 \mathrm{~mm}$ ) because the number of fibers in the ligament in theory should be constant for all notch angle to evaluate the bridging performance of fiber. Furthermore, another three specimens which notch is set on the only parallel two sides $\left(0^{\circ}\right)$ are manufactured to observe crack visually. 
Table 2. Mechanical property of single fiber.

\begin{tabular}{cccc}
\hline $\begin{array}{c}\text { Length } \\
(\mathrm{mm})\end{array}$ & $\begin{array}{c}\text { Diameter } \\
(\mathrm{mm})\end{array}$ & $\begin{array}{c}\text { Tensile strength } \\
(\mathrm{MPa})\end{array}$ & $\begin{array}{c}\text { Elastic modulus } \\
(\mathrm{GPa})\end{array}$ \\
\hline 12 & 0.10 & 1200 & 28 \\
\hline
\end{tabular}

Table 3. Mix proportion of FRCC $\left(\mathrm{kg} / \mathrm{m}^{3}\right)$.

\begin{tabular}{cccccc}
\hline Water & Cement & Sand & Fly Ash & Fiber & Admixture \\
\hline 380 & 678 & 484 & 291 & 26 & 6 \\
\hline
\end{tabular}

Table 4. Fresh property and compression test results.

\begin{tabular}{cccc}
\hline $\begin{array}{c}\text { Temperature } \\
\left({ }^{\circ} \mathrm{C}\right)\end{array}$ & $\begin{array}{c}\text { Air content } \\
(\%)\end{array}$ & $\begin{array}{c}\text { Compressive } \\
\text { strength }(\mathrm{MPa})\end{array}$ & $\begin{array}{c}\text { Elastic modulus } \\
(\mathrm{GPa})\end{array}$ \\
\hline 14.1 & 3.5 & 45.4 & 16.4 \\
\hline
\end{tabular}

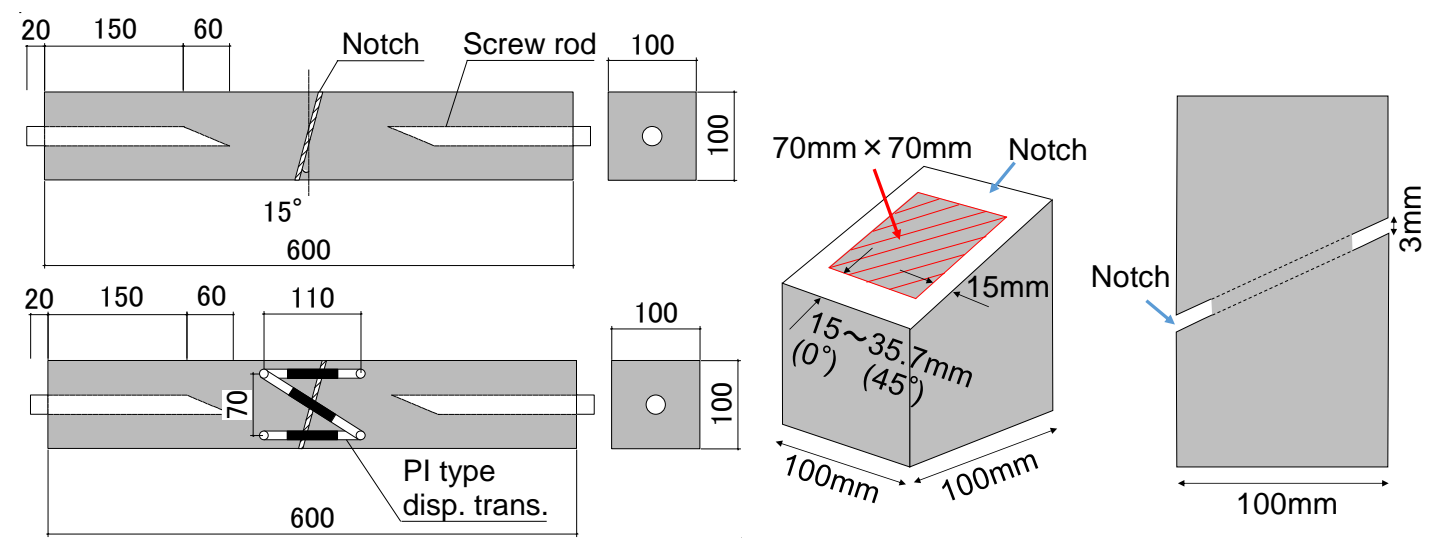

Figure 8. Dimension of specimens (mm). $\quad$ Figure 9. Detail of notch.
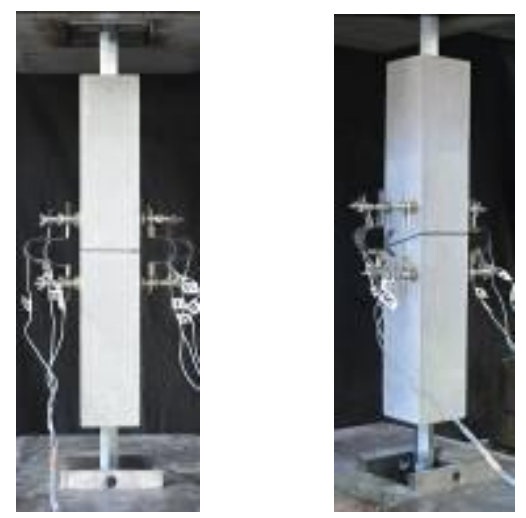

Figure 10. Experimental setup.

Loading and measuring method. The experimental setup is shown in Figure 10. The uniaxial tension tests were carried out using the displacement controlled $2 \mathrm{MN}$ universal testing machine and loading speed was set to $0.5 \mathrm{~mm}$ per minute. The boundary condition in this study is fixed-fixed in order to avoid spinning the specimen at notch. The measuring items were load, the axial and diagonal deformation at the center of specimens. The displacement toward the normal 
direction of crack surface (crack width) and the displacement along crack surface (crack sliding) are calculated based on the measurement. Three displacement transducers were set to two measurement surfaces. In this study, the displacement toward the axial direction of the specimen is called crack displacement (equal to principal crack opening).

Test result. Tensile stress - crack displacement curves are shown in Figure 11 and the examples of the specimens after loading are shown in Figure 12. Tensile stress is calculated from load divided by the area projected ligament onto the surface toward perpendicular to axial direction of specimens (principal tensile stress). Crack displacement is the average value of the displacement measured by four displacement transducers set to the axial direction. Two specimens among three specimens of crack angle $45^{\circ}$ are excepted because perpendicular crack to axial direction outside notch took place. As shown in Figure 11, the maximum tensile stress mostly decreased with increasing crack angle.

In the specimen of crack angle $0^{\circ}, 15^{\circ}$, and $30^{\circ}$, the load decreased after first cracking, and then, the load increased again showing slight increase and decrease. After the maximum load or the second peak load, the load gently decreased. It is considered that FRCC applied in this study forms only one crack in tension test in the case without notch (Kanakubo, et al. 2016). Because the measured load repeatedly increased and decreased in the tests, it is assumed that the plural cracks occurred at the notch, after that, crack opening localized in one crack.

In the specimen of crack angle $45^{\circ}$, the load repeated increasing and decreasing finely. After that, the load sharply decreased, and through a little increment of the

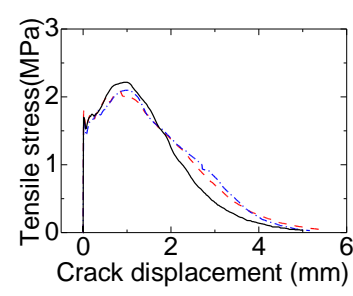

(a) $\mathbf{0}^{\circ}$

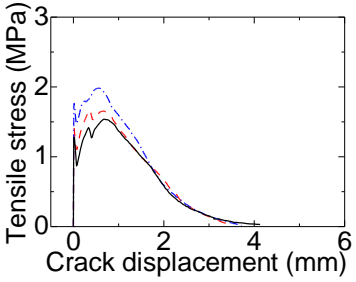

(b) $15^{\circ}$

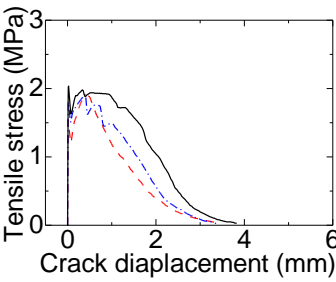

(c) $30^{\circ}$

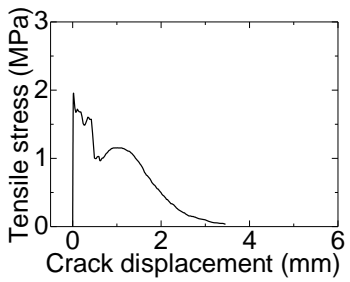

(d) $45^{\circ}$

Figure 11. Tensile stress - crack displacement curves.

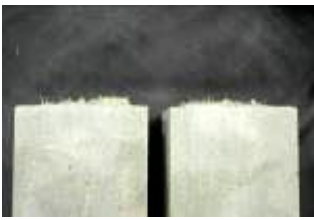

(a) $0^{\circ}$

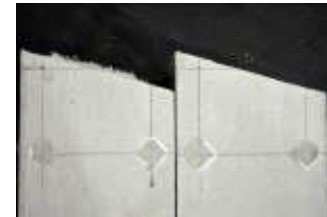

(b) $15^{\circ}$

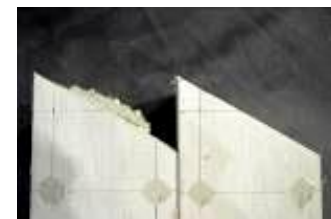

(c) $30^{\circ}$

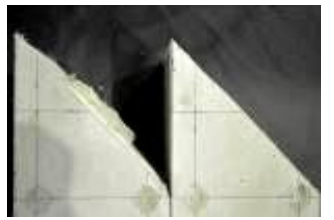

(d) $45^{\circ}$

Figure 12. Photos after loading.
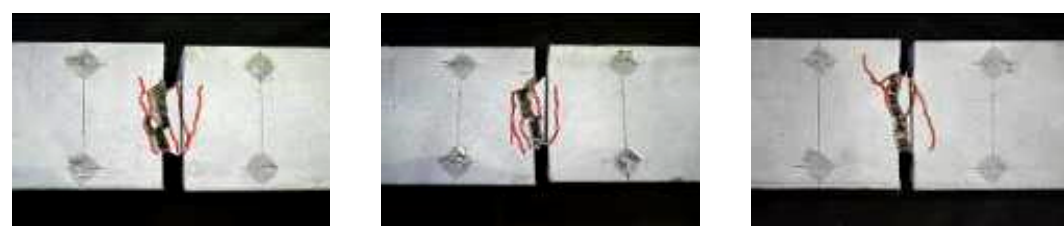

Figure 13. Crack patterns in specimens of notch set on two sides. 
load, the load moderately decreased. It is considered that the sharp decrease of the load is caused by rupture of fibers. Crack patterns after loading in the specimen of the notch of crack angle $0^{\circ}$ on two sides is shown in Figure 13. Cracks were traced by a pen visually at loading. It is confirmed that plural cracks occurred in all specimens.

\section{COMPARISON OF CALCLATION RESULTS WITH TEST RESULTS}

As shown in Figure 11 and Figure 13, it is assumed that all specimens have plural cracks. However, the bridging law is calculated for fibers in one crack surface. In order to compare tension test results with calculated results of bridging law, the measured crack displacement in the tests is modified. It is assumed that the plural cracks occurred in the specimens in which the notch is set on four sides as similar with the specimens of two sides. The measured crack displacement is divided by the average number of cracks observed in two-side-notch specimen to express the displacement per crack until maximum or second peak.

The comparison of tensile stress - crack displacement curves between test results and calculation results of bridging law is shown in Figure 14. The pullout properties of single fiber shown in Table 1 were applied. The orientation intensity $k$ was set to 1 , which is the suitable value for the specimen of the same cross-section in the previous study (Ozu, et al. 2016). The maximum tensile stresses in the calculations are larger than those in the tests in all crack angles. The reason for that is assumed due to the effect of the boundary condition of fix-fix (Kanakubo, 2006). The curves except the maximum tensile stress in calculation results show good agreements with test results. In order to clarify the effect of crack angle, the comparison of the maximum or second peak tensile stress in the tests with calculation results of the bridging law is

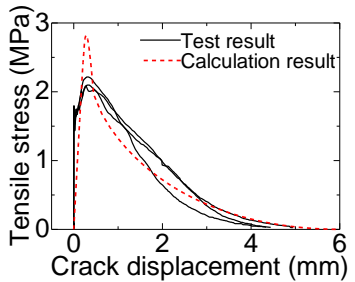

(a) $\mathbf{0}^{\circ}$

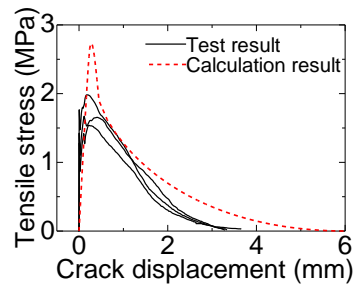

(b) $15^{\circ}$

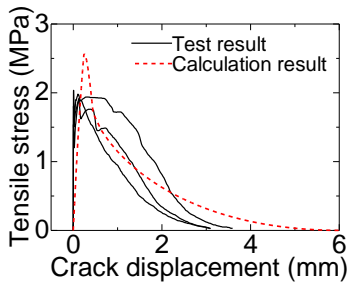

(c) $30^{\circ}$

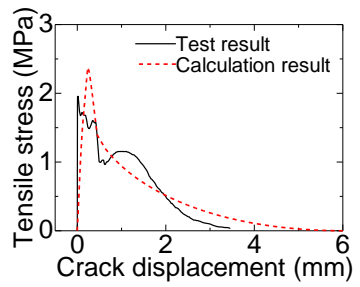

(d) $45^{\circ}$

Figure 14. Comparison of calculation results with test results.

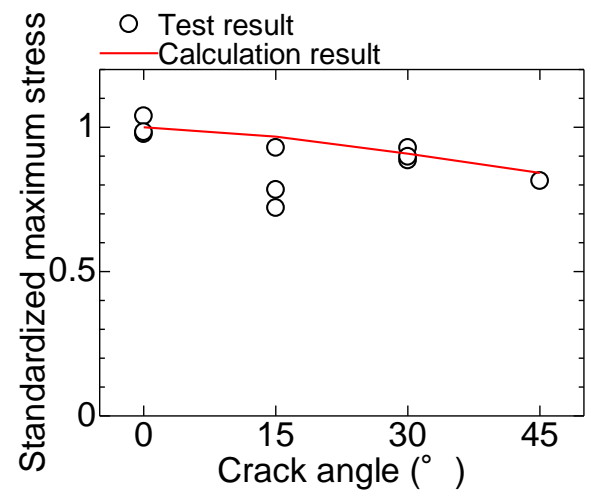

Figure 15. Comparison of maximum stress. 
shown in Figure 15. The maximum or second peak tensile stress is standardized by the value obtained by crack angle $0^{\circ}$. The maximum stress reached in the tests tends to decrease with increasing crack angle, i.e., increasing the angle of pullout force to crack surface, as similar with calculation results.

\section{CONCLUSION}

The tensile test method that simulate the biaxial stress field at crack surface was proposed by tension test specimen with inclined notch. It was confirmed that tensile stress decreased with increasing crack angle in tension tests.

The calculation method of bridging law with inclined crack was introduced and the calculation results were compared with the test results. Though the maximum tensile stress in the tests is smaller than that in the calculation results, the curves after the maximum stress show good agreements with calculations. The maximum stress reached in the tests tends to decrease with increasing crack angle as similar with calculation results.

\section{REFERENCES}

Kanakubo, T. (2006). "Tensile Characteristics Evaluation Method for Ductile FiberReinforced Cementitious Composites", Journal of Advanced Concrete Technology, Vol.4, No.1, pp.3-17.

Kanakubo, T., Miyaguchi, M., and Asano, K. (2016). "Influence of Fiber Orientation on Bridging Performance of Polyvinyl Alcohol Fiber-Reinforced Cementitious Composite", ACI Materials Journal, Vol.113, No.2, pp.131-141.

Kanda, T., and Li, V. C. (1999). "Effect of Fiber Strength and Fiber-Matrix Interface on Crack Bridging in Cement Composites", Journal of Engineering Mechanics, ASCE, Vol.125, No.3, pp. 290-299.

Ozu, Y., Watanabe, K., Yasojima, A., and Kanakubo, T. (2016). "Evaluation of Size Effect in Bending Characteristics of DFRCC Based on Bridging Law", 7th International Conference of Asian Concrete Federation, 3. Concrete structures, Paper No.32.

Yamada, H., Ando, M., Yasojima, A., and Kanakubo, T. (2016). "Effect of Fiber Types on Shear Performance of Precast Concrete Beam-Column Joints Using DFRCC", 7th International Conference of Asian Concrete Federation, 3. Concrete structures, Paper No.46.

Yang, E. H. Wang, S. Yang, Y. and Li, V. C. (2008). "Fiber-Bridging Constitutive Law of Engineered Cementitious Composites", Journal of Advanced Concrete Technology, Vol.6, No.1, pp.181-193. 